\title{
Horizontes do ensino de história na América Latina
}

\author{
Horizons for the teaching of history in Latin America
}

Felipe Ziotti Narita ${ }^{1}$

\begin{abstract}
Resumo
$\mathrm{O}$ artigo desenvolve possibilidades teóricas, desafios e temas para o ensino de história na América Latina a partir de três eixos: (1) as novas construções identitárias pressupostas no giro decolonial, (2) as humanidades digitais e (3) as relações entre o saber histórico e seus públicos à luz dos espaços (físicos e imateriais) de educação. A proliferação de conteúdos da sociedade em rede desloca o saber histórico dos lugares privilegiados da modernidade (sistema escolar), tornando-o mais suscetível à circulação de antagonismos e revisionismos. Além disso, o corrente processo de digitalização de dinâmicas de ensino e pesquisa sinaliza novos modos de existência e contradições de um ensino cada vez mais dependente da infraestrutura imaterial. Em uma conjuntura impactada por mudanças socioculturais e econômicas bruscas, refletir sobre os horizontes do ensino de história implica também considerar o tema da crise das humanidades.

Palavras-chave: Ensino de história;

Humanidades digitais; Crise; Públicos.
\end{abstract}

\begin{abstract}
:
The article discusses theoretical and thematic potentialities on the teaching of history in Latin America according to three topics: (1) the new identitarian constructions underlying the decolonial turn, (2) the digital humanities and (3) the relationship among historical knowledge, spaces of education (both material and immaterial) and the publics in network society. The pervasive effect of digital contents in network society has been shifting historical knowledge from its privileged spaces in modernity (school system) towards a diffuse system that is more prone to the circulation of information, antagonisms and revisionisms. The current digitalization of society highlights new modes of being and new contradictions within teaching activities, which are increasingly dependent on immaterial infrastructure and interactions. In an age of abrupt sociocultural and economic changes, the reflection on the horizons of the teaching of history also implies a broader framework concerning the diagnoses of the crisis of humanities.
\end{abstract}

Keywords: Teaching of History; Digital humanities; Crisis; Publics.

As investigações em ensino de história, a despeito da persistente posição periférica ainda ocupada pela pesquisa histórico-educacional nos cursos de licenciatura e bacharelado em história (MCCULLOCH, 2008; PLÁ, 2012; KUDLÁCOVÁ, 2016), têm assistido a desenvolvimentos significativos na América Latina. Ironicamente, as novas agendas para o ensino de história na região ganham corpo em uma conjuntura marcada por inquietações referentes ao significado do conhecimento histórico diante de reformas curriculares na área de humanidades - como no Brasil, na Colômbia e no Chile (PÉREZ HERRERO; GARCIA

\footnotetext{
1 Pós-doutorado pela Universidade de São Paulo (USP) e Universidade Federal de São Carlos (UFSCar) e doutorado pela Universidade Estadual Paulista (UNESP). Docente do Programa de Pós-Graduação em Planejamento e Análise de Políticas Públicas da UNESP. Membro do Historiar (CNPq) e do Laboratório de Estudos e Pesquisas sobre Infância, Juventude e Educação da USP. Brasil. Contato: felipe.narita@unesp.br 
Fronteiras - Revista Catarinense de História | https://periodicos.uffs.edu.br/index.php/FRCH/index

ISSN 2238-9717 | n. 37, p. 247-270, jul.-dez./2021 | DOI: https://doi.org/10.36661/2238-9717.2021n37.12325

FERNÁNDEZ, 2019; GRANJA MATIAS, 2018; BITTENCOURT, 2018) -, em uma época de aceleração e disrupção tecnológica.

A rigor, as primeiras preocupações com o ensino de história na América Latina estão associadas à conjuntura de formação e rotinização dos Estados nacionais no século XIX, vinculando diversas éticas historiográficas às funções do conhecimento escolar construído e transmitido nas nascentes estruturas de ensino. A produção didática em impressos, construindo o mercado editorial e uma viva cultura letrada em torno de livros de leitura e compêndios, acompanhou pari passu a presença da disciplina história nos currículos escolares (em aulas primárias, secundárias e disciplinas esparsas da formação superior). Além de preceitos metodológicos sobre a objetividade das narrativas e a exposição das matérias (com ênfase sobre as heranças culturais cristãs e a colonização como evolução social e ingresso da região no mundo moderno) (NARITA, 2014; NARITA, 2019), articulando, autores, professores e institutos históricos, diversas traduções e edições aumentadas de livros didáticos de história também circulavam na região (NARITA, 2021b), como os compêndios de Claude Drioux, François-Philippe Mésenguy, Louis-Pierre Anquetil e Giovanni Berti. O didatismo, aliás, favorecia uma relação de aprendizado prático dos vícios e das virtudes do desenvolvimento humano: os editores do compêndio de história americana redigido por Mesa y Leompart (1870), nesse sentido, destacavam o "estilo sencillo" da exposição dos fatos, facilitando as "lecciones que siempre se pueden sacar de la historia cuando se recorren y meditan los acontecimientos".

Subsidiadas por uma vasta gramática moral para a formação de condutas (NARITA, 2017), as propostas de ensino de história também incorporavam as vogas do século, como o evolucionismo e o positivismo, para a reflexão e a composição do gênero didático. $\mathrm{O}$ compêndio de 1880 de Justo Sierra (1984), professor da Escuela Nacional Preparatoria no México, ensinava que a exposição de conteúdos era inseparável de "generalizaciones superiores" abarcadas pela "ley del progresso y de la evolución", dispondo fatos em uma relação estreita de causalidade a fim de demonstrar os processos culturais e políticos que distinguem o desenvolvimento humano. Dialogando com as premissas do evolucionismo social de Justo Sierra, a reflexão de Guillermo Prieto (1888) a respeito da escrita didática da história universal condensava lições de compêndios famosos (Victor Duruy, Cesar Cantú, etc.) à pretensão de uma história que deveria ser ensinada como matéria de sabedoria (próxima do topos ciceroniano da historia magistra vitae), de modo que assinalasse os distintivos morais do humano para "el supremo bien del hombre", deduzindo "doctrinas practicas" (valores e prescrições morais que, embora marcados pelo discurso cientificista do fim de século, 
Fronteiras - Revista Catarinense de História | https://periodicos.uffs.edu.br/index.php/FRCH/index

ISSN 2238-9717 | n. 37, p. 247-270, jul.-dez./2021 | DOI: https://doi.org/10.36661/2238-9717.2021n37.12325

carregavam correspondências com o campo religioso) que pudessem ser transmitidas aos jovens cidadãos.

Uma linha de força traveja as preocupações construídas na aurora da escolarização: a formação de cidadãos. O conteúdo dessa proposta formativa, bem entendido, sofreu torções importantes durante o desenvolvimento latino-americano, de modo que a forte tônica sobre a moralidade religiosa, presente nas propostas oitocentistas e do início do século XX, guarda relações distantes com o horizonte multicultural da cidadania e das demandas plurais por reconhecimento nas democracias liberais dos anos 1980 e 1990 (FLORESCANO, 2006; MANOEL, 2011). Mas o compromisso político com a formação cidadã revela uma justificativa do ensino de história, concebido nos quadros do sistema escolar regulamentado pelos Estados: uma dimensão socializadora do conhecimento, que corresponde a imperativos práticos e morais. Essa perspectiva ainda norteia as linhas gerais de parâmetros legais, livros didáticos, currículos e políticas públicas em ensino de história, mas coexiste com uma miríade de novos problemas decorrentes dos giros modernizadores das sociedades contemporâneas.

O presente artigo delineia temas e abordagens de pesquisa em ensino de história, com ênfase na situação latino-americana, tendo em vista os horizontes socioculturais contemporâneos. O propósito não é apresentar um estado da arte, tampouco um balanço bibliográfico. Antes, a intenção é articular possibilidades e desafios capazes de mobilizar núcleos teóricos e recortes temáticos pertinentes às novas condições e demandas pelo conhecimento histórico. Nesse sentido, a exposição é composta por três movimentos, compreendendo (1) os complexos socioculturais, via ensino, subjacentes às reconsiderações da colonialidade na produção das identidades latino-americanas, (2) as relações entre ensino de história e as funções do conhecimento histórico nos espaços físicos e digitais da cultura moderna e (3) os novos contextos sociotécnicos da dimensão socializadora do conhecimento histórico com seus públicos.

\section{Colonialidade e decolonialidade}

A didática não é apenas um facilitador da aprendizagem (CARDOSO, 2008), como se funcionasse como uma adaptação do conhecimento universitário à escola básica, mas implica uma reflexividade sobre as condições e as fundamentações do ensino da cultura histórica. Nos anos 1990 e 2000, a gradativa e desigual incorporação de novos parâmetros historiográficos ao ensino (GÓMEZ CARRASCO; RODRÍGUEZ PÉREZ, 2017) foi travejada, sobretudo, pela história cultural, pelas mentalidades e pelos textos de Foucault dos anos 1960 e 1970 - já que 
Fronteiras - Revista Catarinense de História | https://periodicos.uffs.edu.br/index.php/FRCH/index

ISSN 2238-9717 | n. 37, p. 247-270, jul.-dez./2021 | DOI: https://doi.org/10.36661/2238-9717.2021n37.12325

a produção foucaultiana do fim dos anos 1970 e início dos 1980, dedicada aos cursos sobre biopolítica, verdade e hermenêutica do sujeito, tornou-se mais difundida apenas recentemente (TRIGO, 2002; CANAVESE, 2015; ARANTES, 2021). Ao passo que o esforço ampliou tematicamente as abordagens e posicionou novas dinâmicas de subjetivação (sexualidade, loucura, poder, etc.), o cenário intelectual fragmentou a noção de processo e a primazia das estruturas socioeconômicas. À luz do discurso da globalização e da reconfiguração das estruturas de bem-estar social do século XX, a agenda ecoou o desgaste do determinismo marxista, o escamoteamento de uma narrativa de história social calcada na agência coletiva das classes sociais e o descentramento de identidades e de posições fixas do sujeito (HALL, 1992).

Se in toto os avanços no ensino (tanto do ponto de vista da incorporação por materiais didáticos quanto junto à prática docente) ficaram aquém das promessas sofisticadas pelas teorias, um esforço de pluralização das narrativas formadoras da modernidade, de algum modo anunciado nos deslocamentos acima mencionados, pavimentou o terreno para outras possibilidades de elaboração historiográfica junto ao ensino de história. Com a crítica póscolonial e a subalternidade, a dissolução da identidade entre ocidente e sujeito do processo histórico denuncia a redução dos antigos mundos coloniais ao signo da falta (FANON, 1952 p. 109; MEMMI, 1982, p. 53): leituras que tematizavam teleologicamente as regiões a partir de carências ou incompletudes (pois dissociadas de uma dinâmica exclusiva ao ocidente europeu) passaram a ser criticadas por reforçar sinais da violência epistêmica decorrente do silenciamento das diferenças e da tentativa de redução dos mundos periféricos e pós-coloniais aos parâmetros dos países centrais (SPIVAK, 1994). Na esteira dessas questões, entre o final dos anos 1990 e o início dos anos 2010, a crítica da colonialidade e as teorias decoloniais ganharam espaço nas ciências sociais latino-americanas. A voga carrega esquemas explicativos de América Latina e, sobretudo, uma crítica da cultura histórica esclarecida pelos traumas regionais e engajada com o descentramento da razão ocidental.

Dentre as diversas propostas decoloniais (MALDONADO-TORRES, 2016), Walter Mignolo (2014) é preocupado com as implicações dos pressupostos explicativos, centrados na prerrogativa da razão ocidental junto à formação do mundo moderno a partir do século XVI, para a educação e a cultura histórica. A crítica deve desvelar a indissociabilidade entre o discurso da modernidade ocidental e a matriz colonial de poder, pois ambos instituem a colonialidade: condição que reproduz nas sociedades independentes os traumas da dominação colonial via dependência econômica, hierarquização sociocultural (gostos, língua, etc.), racismo e o extrativismo sem peias sobre biomas e povos originários. Propondo um "pensamento de fronteira", Mignolo estabelece uma epistemologia que considera a "diferença 
colonial", em uma démarche que escova a contrapelo "o que foi reprimido pela razão moderna" (MIGNOLO, 2010, p. 110). Trata-se de um esforço que introduz, na crítica da dominação do discurso da modernidade, o empuxo para contornar dualismos (arcaico/moderno, modelo/cópia, etc.), reivindicando a heterogeneidade das experiências socioculturais no eixo atlântico e suas margens de invenção sociopolítica (ampliando os referenciais de emancipação do iluminismo, por exemplo, para a novidade da independência haitiana ou as propostas de construção de sociedades nacionais com as independências latino-americanas).

No limite, o compromisso com a construção dessa consciência decolonial implica a abertura do ensino de história à dissolução da narrativa eurocêntrica e à confrontação das formações regionais com a colonialidade. Nesse sentido, a proposta decolonial indica uma política dos saberes no ensino de história enraizada na subalternização das histórias coloniais (lidas como assuntos regionais) e na miragem de universalidade dos processos europeus, cifrando essa relação sob uma temporalidade ditada pela colonização como evolução social e por um movimento linear de afirmação ocidental que meramente desloca (sob o registro da influência) os conteúdos culturais do ocidente para as periferias coloniais - produzindo um nãolugar ou formações sociais desconjuntadas e "fora do lugar" nas periferias. Um efeito didático desta operação pode ser notado no questionamento de um ensino ainda muito confinado às histórias nacionais e à suposta originalidade das criações nacionais (reiterando lugares e nãolugares, bem como a autenticidade e a cópia das ideias), relegando a segundo plano as apropriações e os deslocamentos culturais que caracterizam a modernidade. Outro efeito didático da crítica colonial pode ser entendido mediante a produção de um saber histórico que ressalta como o discurso normativo da modernidade, centrado na autonomia subjetiva, assinala um projeto de emancipação e de esclarecimento indissociável da dominação (CASTROGÓMEZ; GROSFOGUEL, 2007).

Em registro político, o giro decolonial sublinha um horizonte crítico da cidadania ao tematizar diretamente, como em Mignolo (2014), os processos de educação: difundido durante a onda de democratizações na América Latina, o paradigma teórico não deixa de assinalar as fraturas no conceito formal de cidadania (NARITA; KATO, 2020), denunciando tanto a subjugação historicamente construída da região diante da globalização quanto as pressões por democracias participativas e políticas públicas de reconhecimento capazes de dialogar com as singularidades e as vulnerabilidades decorrentes das assimetrias crônicas e suas clivagens étnicas e econômicas. Como une pensée autre, "pensar a partir da diferença colonial implica pensar de outro lugar, imaginar outra linguagem, argumentar a partir de outra lógica" (MIGNOLO, 2010, p. 313), de modo que esse gesto epistemológico pode ajudar a historicizar 
Fronteiras - Revista Catarinense de História | https://periodicos.uffs.edu.br/index.php/FRCH/index

ISSN 2238-9717 | n. 37, p. 247-270, jul.-dez./2021 | DOI: https://doi.org/10.36661/2238-9717.2021n37.12325

as categorias ideais com as quais o ensino de história explica a constituição do mundo moderno (progresso, civilização, modernização, razão, etc.) (RESTREPO; ROJAS, 2010). Se o esforço é importante como procedimento crítico para desnaturalizar pressupostos narrativos e assunções normativas cristalizadas no ensino, nota bene, convém evitar que isso não signifique uma fetichização da diferença, tornando os antigos espaços coloniais irredutíveis às categorias da modernidade, com as quais, aliás, eles lidam em sua formação e pelas quais seus traumas podem ser dialeticamente expostos por meio do confronto entre as promessas subjacentes àquelas categorias e os problemas da efetividade das experiências históricas da integração regional ao capitalismo.

Ao passo que as premissas decoloniais podem descompartimentar as propostas de ensino e reforçar uma construção identitária em que o par modernidade/colonialidade desdobre a dominação indissociável do discurso da modernidade, talvez o principal desafio resida na desconstrução da temporalidade evolucionista ritmada pela colonização. Essa abordagem, difundida por livros e por currículos desde a gênese das estruturas escolares na região, ainda é muito presente e tem sido objeto de pesquisas que articulam as possibilidades de renovação do ensino de história aliadas ao redesenho das políticas públicas educacionais dirigidas aos livros didáticos (FAGUNDES, 2020; FARIA, 2021; RAMALLO, 2017; MESA MADRID; ZÁPATA GIRALDO, 2017). Além disso, do ponto de vista metodológico, os processos de ensino podem ser reforçados pela legitimação de novos recursos documentais (tanto registros escritos e formas de resistência, quanto a abertura de novas concepções de museus e patrimônios) a fim de tematizar a contrapelo os cânones, estabelecidos como visões explicativas, a respeito de uma formação regional relegada a mero efeito da expansão da razão ocidental. Para além da sala de aula e das políticas dirigidas ao público escolar, o reconhecimento da pluralização dos espaços de educação abre perspectivas para as relações de ensino.

\section{Socialização e conhecimento histórico: os espaços de educação}

A construção do saber histórico em sala de aula, entrecruzando documentos normativos, materiais didáticos e currículos, ocupa o foco principal das atenções em ensino de história. Absorvendo referenciais da educação histórica, cognição histórica situada, literacia histórica e didática da história, pesquisas recentes têm mobilizado as competências da matriz disciplinar (perspectiva temporal, contextualização, orientação temporal, experiência, etc.) e indicado possibilidades para o ensino em diálogo com os preceitos formativos dos sistemas de ensino e 
Fronteiras - Revista Catarinense de História | https://periodicos.uffs.edu.br/index.php/FRCH/index

ISSN 2238-9717 | n. 37, p. 247-270, jul.-dez./2021 | DOI: https://doi.org/10.36661/2238-9717.2021n37.12325

das políticas de formação de professores (CARRETERO; MONTANERO, 2008; ANHORN, 2012; SCHMIDT; BARCA; URBAN, 2014; SCHEINER, 2015).

Um deslocamento, contudo, deve ser notado: para além dos quadros da instituição escolar, as preocupações com o ensino de história têm sido dirigidas também para outros espaços de educação (ABUD; SILVA; ALVES, 2010), como museus e educação patrimonial. Esse descentramento das práticas em relação ao campo escolar indica uma dupla alteração. Por um lado, a necessidade de integração de diversos elementos da cultura e das comunidades aos preceitos da formação cidadã pautados na memória social e na responsabilidade individual em relação à preservação das formas culturais e seus acervos. Por outro lado, a pluralização dos espaços de educação implica novas condições de socialização do conhecimento histórico, permitindo maior interface com a sociedade e memórias locais à luz da articulação de modos diversos de tematização didática - pois dissociados da forma escolar - para outros públicos.

Políticas públicas nacionais (como o Guia Básico de Educação Patrimonial, no Brasil, em 1999) e marcos internacionais, como a política de 2003 da Unesco e a Declaração de Freiburg de 2007 acerca dos patrimônios culturais materiais e imateriais, convergem no sentido da valorização da identidade, da pertença social, da sensibilização em relação às heranças históricas no território e da produção de vínculos associados ao campo da educação patrimonial. Não à toa, esses temas formaram uma Stimmung do ensino de história, nos quadros das democracias liberais, a partir dos anos 1980: trata-se de uma alteração do conteúdo normativo (GIDDENS, 2012) das tradições (que possuíam papel de autoridade na integração e na coesão social), de modo que as sociedades contemporâneas ressemantizam as heranças culturais tendo em vista, sobretudo, critérios instrumentais associados ao consumo de massas (turismo, festivais regionais, etc.) e às competências de reflexividade da formação cidadã (sustentabilidade na gestão dos espaços, participação comunitária, etc.).

O patrimônio histórico, então, é ligado a uma política de reconhecimento: os artefatos da tradição são concebidos como expressões históricas significativas para uma comunidade, ou seja, como formação de uma consciência histórica que identifica a cidadania como direito de acesso a bens culturais definidores das coletividades (monumentos, gastronomia, costumes locais, arquitetura, etc.). Diversas experiências de educação patrimonial no Chile, Argentina, Brasil, Venezuela, México e Colômbia (FLORESCANO, 1997; GARCÍA VALECILLO, 2007; FONTAL MERILLAS, 2016) têm mobilizado esses espaços de educação, vinculando o ensino de história à produção de saberes regionais e a uma cultura histórica ligada à proliferação de memórias locais e nacionais. Essas narrativas descentradas dos discursos históricos de legitimação confinados nos livros didáticos e na sala de aula também modulam os parâmetros 
Fronteiras - Revista Catarinense de História | https://periodicos.uffs.edu.br/index.php/FRCH/index

da consciência histórica moderna, que tende a classificar e a privilegiar o valor simbólico dos bens culturais conforme o cânone historiográfico das origens nacionais, dos grandes fatos e dos personagens (POMIAN, 2003).

Como espaços de educação integrados ao ensino de história e que primam pela materialidade dos bens culturais, as instituições permitem uma aproximação crítica com o próprio discurso da identidade (MENESES, 1993; CAMERON, 1971), desnaturalizando a aura investida aos objetos e desvelando as condições sociais de apropriação pela prática museológica e de produção do valor cultural dos artefatos. Em outras palavras, esse esforço desfaz o fetiche de que o objeto expressa per se um discurso sobre a identidade cultural, ofuscando as práticas sociais que conferem sentido e intenções aos lugares de memória ocupados pelos bens culturais.

Museus e acervos culturais de memória não são restritos às coleções, mas são mediadores de apropriações e usos sociais dos bens culturais, tendo em vista a equação entre desenvolvimento territorial e construção cultural de uma comunidade (VARINE, 1991). Nesse sentido, curadorias compartilhadas e requalificação de coleções à luz da interculturalidade e da crítica da colonialidade, como os museus indígenas (ROCA, 2015; CURY, 2017), conferem visibilidade e espaços de educação cidadã organizados em rede (como a Rede Indígena de Memória e Musologia Social, o Programa Pontos de Memória, etc.). Além disso, essas experiências tematizam as disputas e os silenciamentos da cultura histórica, constituindo também arenas políticas para a valorização das diferençás étnicas nos discursos normativos sobre a nação - escamoteadas sob a tônica civilizadora das narrativas de formação da América Latina. Ao reforçar a crítica de narrativas nacionais estabelecidas e alinhar a educação da consciência histórica com o giro decolonial, a paisagem museal parece ressoar questões mais amplas de uma esfera pública em que os signos históricos são cada vez mais disputados e revistos.

Aqui, um horizonte fundamental para o alargamento das reflexões sobre ensino de história diz respeito à inserção dos espaços de educação no conjunto mais amplo da esfera pública contemporânea. A crescente atenção aos espaços de educação, como museus, bibliotecas e projetos de educação patrimonial, ressalta as possibilidades de construção de um público capaz de construir opiniões, condição da publicidade crítica (HABERMAS, 1990, p. 356-357), pois mediado pela reconfiguração de uma esfera pública sensível às divisões ideológicas e à extensão do saber histórico escolar, tematizando publicamente os traumas da cultura histórica. Uma das principais conquistas das pesquisas em ensino de história desde os anos 1980, especialmente a partir dos esforços de Jörn Rüsen (1989) pela vinculação entre as funções pragmáticas (didáticas) e a matriz disciplinar, repousa nas conexões entre o ensino e a 
configuração da cultura histórica, entendida como o as relações e os sentidos construídos pelas coletividades com o tempo histórico. Em registro amplo, a história ensinada nos espaços de educação é desdobrada sobre os usos do passado e sobre os modos como as sociedades lidam com o saber histórico (PANDEL, 2006; PANDEL, 2017), y compris o esforço de autocompreensão dos traumas e dos conflitos subsumidos ou pretensamente amainados sob registros identitários nacionais (FONSECA; NARITA, 2018).

$\mathrm{Na}$ América Latina, é sintomático o movimento de muitas instituições museais, acompanhando o discurso da cidadania a partir dos anos 1990, no sentido do engajamento com os impasses históricos. A tangibilidade de uma ética do ensino de história comprometido com a democracia reside em lidar criticamente com o passado em vez de escamoteá-lo. Em 2011, o projeto do Museo de Memoria da Colômbia reivindicava um espaço coletivo para a reconciliação e a abordagem do conflito armado, indicando o compromisso público com uma história do presente. O Museo de las Memorias, Dictadura y Derechos Humanos do Paraguai, o Memorial da Resistência de São Paulo, o Museo de la Memoria do Uruguai e o Museo de la Memoria y los Derechos Humanos do Chile, por meio de projetos de educação, materiais didáticos, ferramentas de divulgação científica, interação online e visitas de turma, articulam a dimensão socializadora dos espaços de educação ao confrontar o ensino com a publicização dos rastros e dos testemunhos da violência política estatal durante as ditaduras militares. Esse dever de justa memória encampado pelos espaços de educação subsidia a publicidade crítica com documentos e com pesquisa - política importante em uma época suscetível ao negacionismo e à relativização dos regimes de exceção na região (GIORDANO; RODRÍGUEZ, 2019).

As transformações sociotécnicas das últimas três décadas, tornando o digital onipresente, alteraram as relações com os espaços de educação. O ensino de história não é apenas influenciado por parâmetros curriculares ou correntes teóricas, mas pelo próprio meio de difusão da cultura histórica materializado nas novas infraestruturas de rede (CRYMBLE, 2021). Se as conexões remotas e o volume de informação desterritorializam e desmaterializam a cultura em dados, a multilocalidade dos conteúdos implica condições de difusão e de acesso ímpares. Do monopólio dos espaços de educação tradicionais (escolas, museus, bibliotecas, conjuntos arquitetônicos, etc.) à proliferação de canais de conteúdo histórico na sociedade em rede, uma alteração na legitimação do saber histórico parece ganhar corpo no horizonte do ensino de história. 
Fronteiras - Revista Catarinense de História | https://periodicos.uffs.edu.br/index.php/FRCH/index

ISSN 2238-9717 | n. 37, p. 247-270, jul.-dez./2021 | DOI: https://doi.org/10.36661/2238-9717.2021n37.12325

\section{O ensino de história e os públicos na sociedade em rede}

A partir dos anos 2010, com a popularização de smartphones, laptops e da web 2.0 nas economias mais avançadas da América Latina (CEPAL, 2018), a difusão de canais virtuais para ensino de história alterou não apenas o formato de divulgação disponível nas mídias de massa (como o History Channel ou os documentários do National Geographic), mas inseriu o ensino na lógica social das redes, pulverizando e diversificando ainda mais os públicos. A socialização sofre uma inflexão significativa: os gostos tendem a ser mais individualizados, já que as condições de consumo e de participação favorecem a fragmentação cultural (SORJ; MARTUCCELLI, 2008, p. 78-80) diante da pluralidade de opções em conteúdos digitais cada vez mais segmentados em nichos. Não se trata da relação emissor-receptor, mas de uma interação que permite bricolagens, múltiplas combinações de dados, modificações de conteúdos e acesso simultâneo a diferentes plataformas (TERRANOVA, 2004). Além de difuso, portanto, o ensino de história na sociedade em rede torna cada indivíduo uma unidade produtora de conteúdo digital (MORELOCK; NARITA, 2021), ou seja, com recursos básicos da infraestrutura de rede é possível transmitir e interagir com os dados da esfera pública via estímulos e uma estética própria ancorada em imagens, sons, efeitos visuais e hipertexto. $\mathrm{O}$ ensino de história é abordado a partir de uma dupla pressão: uma mudança da infraestrutura técnica que subsidia uma miríade de relações sociais rotinizadas praticamente diante do saber no meio digital (compartilhamento, instantaneidade, captura de atenção, acessos simultâneos a plataformas diversas, hipertexto, buscas otimizadas, etc.). Por isso, enfatizo a emergência de uma nova configuração sociotécnica diante do saber e de suas formas de legitimação nas redes.

Mesmo espaços de educação tradicionais, como museus e bibliotecas, não são depósitos de uma tradição inerte, mas mobilizam recursos interativos para uma educação histórica sintonizada com a flexibilidade do consumo cultural contemporâneo (BALDACCI, 2016; LEGÊNE; AKKER, 2020), atendendo tanto à erudição quanto à atração dos públicos difusos. Muitas mostras e acervos, uma vez indexadas em plataformas capazes de processar dados de milhões de itens digitalizados, estruturam disposições randômicas de conteúdos (MANOVICH, 2017), de modo que esses espaços de educação não são orientados apenas por catálogos institucionais ou fichas bibliográficas, mas por um pot-pourri de imagens que, em uma mesma visita, exibem de um estudo para piano de Scriabin a fotografias da Revolução Mexicana, fragmentando a própria noção de unidade de um arquivo ou coleção cultural.

Na lógica das redes, não há homogeneização nem transmissão unilateral dos conteúdos, como na sociedade de massas dos séculos XIX e XX, mas maior possibilidade de interação (mensagens instantâneas, likes, etc.) e reprodução (compartilhamento). Comportamentos e 
preferências, então, são mapeados remotamente pelas políticas de dados, exibindo conteúdos potencialmente mais afeitos aos gostos individualizados em newsfeeds, listas de reprodução, etc. O fato sociológico mais significativo dessa nova legitimação do conhecimento histórico talvez seja a dispersão dos públicos. A diferenciação oferecida por Wright Mills (1999, p. 303304) entre público e massa pode ser operacional para o entendimento dos novos canais de divulgação e ensino de história. Ao passo que os fenômenos de massa pressupõem maior passividade e unidirecionalidade dos conteúdos - padronizados e distribuídos via meios de comunicação de massa (televisão, impressos e rádio), tendo margens mais restritas para interação e para a publicidade crítica das opiniões -, o público implica maior proatividade e capacidade de difusão e processamento de informações disseminadas. A massa é concentracional e tende a homogeneizar, ao passo que o público é disperso em singularidades. No caso das redes, esse referente da comunicação é fragmentado e segmentado em muitos públicos, com sujeitos remotos que acessam e interagem praticamente de qualquer lugar e a qualquer momento, além de ser ainda mais indeterminado, pois não há necessariamente produção de vínculos entre os sujeitos (como em uma sala de aula ou em um auditório) e os conteúdos digitais comumente não possuem um destinatário específico.

Esse trânsito ao digital no ensino é notado, ainda de modo tímido, junto à infraestrutura de centros de pesquisa consolidados, que difundem conteúdos de história por canais híbridos de educação (mesclando o físico e o digital), como as plataformas da USP, Unesp, UFRGS e UFSCar - além do acervo da Univesp, uma universidade virtual pública mantida pelo governo de São Paulo no Brasil. Sintomática, nesse sentido, é a criação da área de história digital, em 2019, no Instituto de História Argentina e Americana da Universidade de Buenos Aires, tendo como foco a ampliação do acesso ao conhecimento ao explorar as tecnologias de rede. Os verbetes online sobre personagens e processos da história brasileira publicados pela Biblioteca Nacional e pela FGV, facilmente acessíveis e indexados nos mecanismos de busca, também são bons índices da abertura institucional à proliferação de conteúdos históricos consistentes nas redes, indicando informações sintéticas e referências que atendem às necessidades de professores, estudantes e interessados em história.

As humanidades digitais não são apenas a tradução de conteúdos para o meio digital, mas uma condição do saber escolar em ciências humanas que, dialogando com a infraestrutura de armazenamento e circulação de dados, vincula a docência, a pesquisa e a aprendizagem às novas relações sociotécnicas das redes. $\mathrm{O}$ aporte computacional em pesquisa social quantitativa tem sido recorrente desde os anos 1960 e 1970. Um historiador como Emmanuel Le Roy Ladurie, à época, afirmava que o historiador deveria ser também programador (LE GOFF, 2006, 
Fronteiras - Revista Catarinense de História | https://periodicos.uffs.edu.br/index.php/FRCH/index

ISSN 2238-9717 | n. 37, p. 247-270, jul.-dez./2021 | DOI: https://doi.org/10.36661/2238-9717.2021n37.12325

p. 58), tendo em vista a possibilidade metodológica de seriação de dados e processamento de informações relativas a mapas populacionais, dispersão demográfica e movimentos conjunturais na economia. Na mesma direção, Edward Shorter (1971) reconhecia o papel auxiliar dos nascentes processos de digitalização na preparação de materiais de ensino e de pesquisa quantitativa.

Contudo, a popularização das redes nos anos 1990 e 2000 alterou esse quadro: não se trata mais da incorporação instrumental ou metodológica de computadores para questões tópicas, mas de uma área vinculada à lógica do digital. Os modos de socialização e de ensino do saber histórico, cada vez mais dependentes das práticas de rede (tanto para condução de aulas remotas quanto para recursos didáticos utilizados em sala de aula), situam-se em um ambiente já totalmente generativo (pois autonomizado dos modos analógicos) a partir do compartilhamento, métricas de acesso/exibição, buscas otimizadas e indexadores de conteúdo. A ponta mais visível das humanidades digitais está na disponibilização de recursos para ensino e pesquisa: além dos espaços de educação, vale destacar os novos formatos de publicação (advance online publication, divulgação científica em blogs e jornais, etc.) e as enciclopédias digitais (como o portal da Enciclopédia Latinoamericana, da Boitempo) que permitem trânsitos rápidos entre os verbetes, compartilhamento e conexões externas. Diversos consórcios latinoamericanos em ciências humanas não apenas buscam uma adequação aos formatos mais fragmentados de eventos acadêmicos, propiciado pela interação remota (como a Red Latinoamericana para el Cambio Social y el Aprendizaje Emancipatorio, cujo congresso de 2021 foi disperso em semanas diferentes), mas deslocam as próprias apresentações e encontros para webinários permanentes transmitidos remotamente. A portabilidade dos dados altera muito as relações de ensino, uma vez que, embora sejam produzidos em um lugar imaterial (LOUKISSAS, 2019), os dados são indexados por fontes muito diversas e podem ser replicados ad infinitum e livremente editados, via moodle, wikis, fóruns e recursos interativos das platform studies, introduzindo novas relações e tensões entre cópia e originalidade, reprodução e autoria.

Um duplo movimento é sintomático para a manipulação dos objetos digitais e para as novas condições de difusão do saber histórico. Primeiramente, vale destacar os projetos de digitalização de acervos, cada vez mais abertos à pesquisa e ao provimento de recursos para o ensino, referentes à hibridação das práticas culturais (SCHNAPP; PRESSNER, 2015), ou seja, signos da transição de um mundo armazenado exclusivamente em infraestrutura física para uma nova forma de curadoria cultural digital. Nesse caso, além da célebre coleção sobre o pensamento latino-americano da Biblioteca Ayacucho (Venezuela), as bibliotecas nacionais da região (Argentina, Brasil, México, Chile, Colômbia, Equador e o Sinabi da Costa Rica) 
atualmente atravessam grandes processos de digitalização com a estruturação de coleções e mostras digitais a fim de abrir os acervos para atividades escolares e para pesquisa. Se alguns formatos, como a Biblioteca Digital de Bogotá, permitem a personalização de coleções e contam com participação dos usuários para indexar conteúdos, a abrangente plataforma da Biblioteca Digital del Patrimonio Iberoamericano digitaliza vastos acervos regionais e sinaliza redes de cooperação transnacionais que redefinem a identidade do espaço ibero-americano por meio de uma política cultural de acesso aberto. Isso delimita uma memória social compartilhada pela proximidade linguística e histórica da região, mas viabilizada pelas humanidades digitais por meio do conceito de interoperabilidade dos catálogos, ou seja, oferecendo buscas cruzadas por metadados, conforme o sistema Dublin Core, capazes de cruzar as referências de todos os objetos digitais das instituições parceiras.

Entretanto, o acesso remoto, a relação com novos públicos, a ampliação dos mecanismos colaborativos e os diversos níveis de interação entre usuários e conteúdos não podem ser reduzidos a um determinismo tecnológico, como se a infraestrutura espontaneamente possibilitasse esses horizontes para o ensino. É preciso, antes, garanti-los por meio de políticas públicas. Com a integração das demandas por história e das dinâmicas de ensino junto à infraestrutura digital, um dos horizontes para a área passa pela incorporação e pela construção de novas relações sociotécnicas identificadas pela redefinição de bem comum junto aos novos circuitos de produção social abertos pelas redes (BENKLER, 2006). Trata-se, portanto, de pensar práticas e éticas que subsidiem o acesso aberto em humanidades digitais, tendo em vista o enriquecimento do ensino de história a partir do potencial das formas cooperativas do trabalho docente e imaterial, como estratégias de co-gestão e de co-utilização remota de recursos.

Essa gramática social tem sido acompanhada por políticas específicas para que o acesso e o uso dos conteúdos sejam democratizados via expansão de licenças abertas (os comuns, commons) baseadas em alternativas à lógica proprietária, que subsume as permissões de acesso e de manipulação de itens digitais a direitos de reprodução. Os comuns sinalizam a importância do governo social sobre os bens culturais, ressaltando a circulação do conhecimento como práticas de compartilhamento determinadas pelas coletividades. Os recursos de ensino, tematizados sob a lente dos comuns, são parte de um dilema ético da internet referente a como desenhar políticas para uma rede que seja um bem público capaz de, a um só tempo, regular o avanço da lógica proprietária e permitir o acesso aberto (GRECO; FLORIDI, 2004), sobretudo, a itens culturais (artigos científicos, fotografias, vídeos, pinturas, impressos e música) que definem nosso patrimônio histórico e orientam a reprodução social ao subsidiar materiais para o ensino. 
Fronteiras - Revista Catarinense de História | https://periodicos.uffs.edu.br/index.php/FRCH/index

Mas uma política cultural para os comuns resvala em problemas estruturais. Por um lado, os comuns são apresentados como um espaço que não é público nem privado, ou seja, não pode ser apropriado nem sujeito ao controle estatal (por isso, trata-se de um comum). As disputas pelos comuns moveram alguns conflitos sociais pós-socialistas (NARITA, 2018b) e sinalizaram novas fronteiras de expansão dos mercados (NARITA, 2018a), de modo que o incentivo e a garantia de acesso aberto, uma vez respaldados por políticas públicas, precisa entender o Estado como indutor de parâmetros legais que legitimem as licenças abertas, evitando novos enclosures. Por outro lado, a legislação moderna é amparada em uma difusa tradição liberal construída junto aos Estados nacionais nos séculos XVIII e XIX e expressa hoje no modelo de copyright (BETTIG, 1996; LESSIG, 1999; SÖDERBERG, 2002), que concede primazia a direitos individuais e a uma socialização fiada por proprietários. Por isso, os comuns exigem uma nova pactuação entre as relações de mercado (baseadas na apropriação privada) e os direitos coletivos (ROSNAY; STALDER, 2020; NARITA, 2020) à luz de um entendimento do acesso livre aos bens digitais como plataforma de desenvolvimento social e humano no século XXI. Os recursos das humanidades digitais não são externalidades à consecução das tarefas do ensino, mas elementos indissociáveis para a participação na cultura histórica e para o engajamento cidadão em sua preservação e valorização.

Outro horizonte do ensino nas humanidades digitais diz respeito a um saber histórico que já é nativo digital e consegue atualizar os contatos com os públicos. Novos discursos de legitimação do conhecimento histórico tomam corpo em uma miríade de iniciativas individuais ou de pequenos grupos, assumindo muito mais dinamismo do que as instituições escolares da modernidade. Canais virtuais de ensino de história na América Latina, com enfoque em conteúdos da educação básica, utilizam os serviços de grandes plataformas, como YouTube e Facebook, e são muito acessados. HistoriaEn10' (Argentina), Resumes Entelekia (Argentina), Historizando (Brasil), Se Liga Nessa História (Brasil), HugoX ChugoX (Peru) e Cultopedia (Colômbia) imprimem dinamismo aos conteúdos do ensino escolar, com ilustrações, acervos culturais, links, flip classroom de lições de 15 minutos, etc. Conteúdos históricos de ensino superior e intervenção no debate público também são presentes nesses novos formatos, como a experiência do projeto Matrizes Políticas (Brasil): embora seja produzido por especialistas e acadêmicos do Rio de Janeiro, vinculados à UERJ, os formatos são acessíveis ao cidadão cultivado com interesse em história do pensamento político.

Nas últimas duas décadas, as discussões sobre ensino também estão associadas às preocupações da história pública (CAUVIN, 2016), tendo em vista as conexões entre a pesquisa especializada e as demandas sociais tangenciadas pelas disputas sobre o passado (FONTANA, 
2004) e pelo lugar do conhecimento histórico rigoroso - derivado da formação específica na área - junto às novas mídias. Por isso, indissociável da análise sobre o lugar do ensino de história é a consideração da mobilidade dos novos públicos. Se não se trata apenas do modelo de uniformização do público escolar - baseado em turmas delimitadas, presença física, etc. -, o caráter remoto e multilocal dos públicos redesenha a própria demanda por história e pelo ensino. Em artigo recente sobre a crescente virtualização das experiências de ensino de humanidades, Agamben (2020) lamentou a barbarie tecnologica como estreitamento da experiência e perda do contato, tornando a socialização refém da schermo spettrale. Ainda que a denúncia do filósofo italiano seja compreensível em função da mudança abrupta das relações didáticas no meio virtual (pensando nas relações de sala de aula e no impacto da pandemia no ensino), a difusão virtual de conteúdos do ensino de história ocupa lugar crescente nas experiências de aprendizagem de estudantes e de indivíduos interessados nas humanidades. Essa multimodalidade da cultura digital, que compreende canais de divulgação, aulas abertas, lives, mídia, rede social, etc., é tão impactante quanto foram a cultura dos impressos no século XIX e o rádio e a televisão no XX. Trata-se de um caminho sem volta que pode ser explorado para a reconstrução das premissas de emancipação da educação (tema que será discutido na próxima seção).

A transformação sociotécnica carrega sinais ambíguos. As humanidades digitais e as mídias oferecem plataformas de acesso inconcebíveis há até poucas décadas, golpeando o entendimento com um volume nunca antes visto de métricas e informação. Em termos de disponibilidade e produção de conteúdos de ensino e de formação da consciência histórica, essa vertigem pode reforçar a superficialidade, comprometendo a maturação e a interpretação detida de temas do ensino de história. Além disso, as assimetrias socioeconômicas reiteram os bolsões de exclusão, uma vez que a digitalização depende de infraestrutura de rede, pacotes de dados e conexões rápidas para que os objetos sejam plenamente acessíveis. Conforme pesquisa de 2020 do Banco Mundial (BEYLIS et al., 2020), na América Latina 50\% da população não têm acesso a conexões de banda larga em um contexto de incorporação de tecnologias $5 \mathrm{G}$ e de mudanças sociotécnicas drásticas no trabalho, na disponibilidade da informação e na reprodução cultural. Essa situação de privação social vem sendo definida como "pobreza digital" e afeta particularmente as áreas menos urbanizadas e as periferias dos países na região (PETRAZZINI, 2007), já que a incorporação do substrato técnico decorrente dos giros modernizadores é muito desigual. No limite, a inclusão e o letramento digitais devem ser objetos de política pública, na medida em que o desenvolvimento social em economias nucleadas no mercado - incapaz de corrigir, por si só, as desigualdades por ele geradas - depende da indução redistributiva do 
Fronteiras - Revista Catarinense de História | https://periodicos.uffs.edu.br/index.php/FRCH/index

ISSN 2238-9717 | n. 37, p. 247-270, jul.-dez./2021 | DOI: https://doi.org/10.36661/2238-9717.2021n37.12325

Estado para lidar com as expressões de exclusão sociocultural e econômica. A infraestrutura digital é um bem básico para qualquer agenda de desenvolvimento, pois a inclusão digital viabiliza instrumentos de poder que afetam a participação cidadã (RHEINGOLD, 2000), sendo elemento-chave para os horizontes do ensino de história e de formação docente, articulando potencialidades culturais dos espaços de educação e, por meio da conectividade, construindo canais com os públicos.

Ademais, há uma camada sociocultural subjacente aos formatos de difusão e de ensino das redes. A nova condição da nossa experiência histórica diante dos públicos expõe um sinal problemático: a consciência histórica é um modo de ser público (Öffentlichseins) da vida (HEIDEGGER, 1988, p. 54-55), ou seja, só coloca em circulação os temas à medida que estes interessam ao horizonte coletivo da existência (HEIDEGGER, 1988, p. 62-63). A consciência histórica, expressa em narrativa, tenta estabilizar o sentido de uma gramática comum (vínculos e pertença) em um fenômeno público que circula entre a identidade individual e a memória coletiva, submetendo o ensino e o debate dos conteúdos históricos à impessoalidade dos públicos. Justamente por isso, a consciência histórica é sujeita a um crescente conflito de interpretação decorrente da fragmentação cultural e ideológica contemporânea. O papel do ensino de história em sociedades acossadas pelo imediatismo e pelos bouleversements de fraturas identitárias e políticas não deixa de carregar também os signos de uma crise mais ampla que diz respeito às humanidades, tanto em sua fundamentação prática quanto em seu lugar em uma época de pós-verdade e de precarização das carreiras docentes.

\section{Do ensino de história à crise das humanidades}

A discussão sobre o ensino de história traz um indisfarçado desassossego diante da relevância das humanidades na sociedade contemporânea. Por isso, um dos maiores desafios para a história diz respeito à justificação de sua atualidade e função prática. A precarização da área, a rigor, não é nova: as demandas por instrução tecnicizante e o império pragmático da razão instrumental, especialmente a partir da segunda metade do século $\mathrm{XX}$, têm relegado atividades mais reflexivas a uma posição secundária. Se diagnósticos tão diversos como os de Hannah Arendt, Paul Valéry e Theodor Adorno sinalizavam as transformações no status das humanidades e da erudição junto à exigência pragmática da cultura contemporânea, John Plumb (1964) e W. David Maxwell (1969) eram assertivos diante da sensação de crise das disciplinas humanísticas à luz do boom tecnológico a partir dos anos 1950 e 1960 e da tecnificação de uma formação profissional cada vez mais fetichizada pelas áreas aplicadas. 
Fronteiras - Revista Catarinense de História | https://periodicos.uffs.edu.br/index.php/FRCH/index

Além disso, a pulverização e a dinâmica remota dos públicos, segmentados em nichos, tendem a amplificar as disputas pelo passado, distorcendo as próprias condições de engajamento da cidadania, por exemplo, com o loop de polarizações e discursos de ódio que são produzidos e reproduzidos em velocidade crescente (GARCIA CANCLINI, 2020). A facilidade para difusão de revisionismos rasteiros e a perda de monopólio das instituições legitimadoras dos saberes na modernidade (universidade, institutos de pesquisa, escolas, etc.) podem conduzir a uma entropia cognitiva em que a consistência intelectual e o exercício crítico - condições da autonomia subjetiva moderna - sejam obnubilados pela crescente reificação de relações sociais danificadas por formatos unidimensionais de socialização na época da pósverdade.

A pós-verdade é uma lógica cultural que desestabiliza o reconhecimento de dados objetivos como nortes da opinião pública, deslegitimando a ciência estabelecida a fim de reduzir o debate a um confronto de meras opiniões ou de denunciar a fabricação de consensos científicos. O fenômeno, portanto, não é novo. Tampouco são novas as falsificações que distorcem a realidade (fake news). A novidade da pós-verdade está na convergência entre a nova infraestrutura técnica e as relações sociais propiciadas pela democracia: reside, portanto, em uma dupla condição sociotécnica relativa à (1) capacidade de difusão da informação e (2) ao problema da participação, dos consensos e dos conflitos na democracia liberal. Em conjunto, essas dimensões alimentam uma crise permanente no discurso da ciência.

Em relação ao primeiro ponto, além do volume e da velocidade dos dados, a dispersão dos públicos e sua segmentação conforme preferências reforçam a capacidade de construir pontos de vista concatenados por estratégias de convencimento (narrativas), de modo a adequar a realidade a visões subjetivas ou a produzir desorientação com questionamentos sobre a legitimidade do saber instituído. Aqui fica exposto o paradoxo epistemológico da pós-verdade: ela pode reivindicar as mesmas pretensões e fundações teóricas da verdade (BUFACCHI, 2020), ou seja, aplica os procedimentos da ciência sobre ela própria, mas radicaliza conclusões capazes de gerar sensacionalismo e promover o menoscabo pelo conhecimento decorrente da formação profissional. Nesse sentido, a pós-verdade lida com a fratura dos consensos (ANDINA, 2019), utilizando discordâncias da comunidade científica - ou opiniões paralelas capazes de alimentar o negacionismo - a fim de expor os paradigmas estabelecidos como maquinações das elites. O segundo ponto diz respeito aos contextos comunicacionais das democracias liberais, que estão estruturadas sob um quadro normativo em que a estabilidade institucional depende da produção de consensos e de debates mediados por razões. No entanto, mais importante do que os consensos é a dificuldade de lidar com os conflitos gerados pela 
própria dinâmica democrática: se a democracia liberal promete participação cidadã e permite maior expressão da sociedade civil, divergências sobre questões públicas (como a história ou a memória social) serão tematizadas cada vez mais abertamente como motores das relações sociais, especialmente em uma época de superexposição de opiniões.

Dentre as alternativas para mitigar o problema, ganham contorno diversas propostas de políticas públicas sobre monitoramento institucional (com fiscalização dos poderes públicos sobre eleições, redes, etc.) e reforço da esfera pública, via imprensa, para combater a desinformação. Uma dimensão, contudo, não pode ser negligenciada: o compromisso intelectual do historiador com a crítica e o papel do ensino de história. A história pública, como intervenção no debate corrente, é importante para constituir espaços de esclarecimento dos públicos a partir de parâmetros das ciências sociais. Se o lugar e as funções do intelectual mudaram, os espaços de educação permitem maior volume de intervenção com a multimodalidade das humanidades digitais. Nesse cenário, o processamento das fraturas culturais e da crise epistemológica da época da pós-verdade pode contar com uma refuncionalização da esfera pública se os profissionais ocuparem espaços para a reconstrução de uma noção de crítica que não abdique do conhecimento histórico para a orientação de sentidos da vida social e para a emancipação intelectual.

Mas a questão da pós-verdade não exige apenas uma ação pontual: por isso, o ensino da história implica um processo formativo que tem como premissa a matriz disciplinar e os procedimentos que legitimam cientificamente a área (pesquisa documental, crítica documental, conceitos, bibliografia especializada e discussões de profissionais). No limite, a pós-verdade corrói a proposta de emancipação da educação, pois não é possível construir autonomia intelectual sem uma reflexão ponderada sobre os parâmetros que constituem o conhecimento histórico, a crítica dos processos históricos que ressoam nas contradições da sociedade contemporânea e a análise dos valores humanos que instituem a socialidade como nossa condição mediada por valores partilhados em um mundo comum. A aposta formativa pode ser um retorno prático das humanidades para a sustentabilidade da própria democracia (NUSSBAUM, 2010), cuja exigência não implica apenas treinamento para cumprir tarefas, mas reflexão - contraparte do ideal de cidadania - para alimentar formas de aprendizagem, fundamentadas na ciência, que suscitem o engajamento e o questionamento dos fenômenos socioculturais para a desnaturalização de pressupostos que aparecem como válidos. Fundamental, no horizonte do ensino de história, é a retomada de uma consciência formativa de sujeitos responsáveis pela construção do mundo histórico diante da proposição de horizontes condizentes com as agendas de coesão social do século XXI, travejadas pelos direitos humanos, 
Fronteiras - Revista Catarinense de História | https://periodicos.uffs.edu.br/index.php/FRCH/index

desigualdades, reconhecimento, redistribuição e inclusão: núcleos estruturantes dos impasses latino-americanos aguçados pela recente pandemia, sem os quais qualquer reconciliação, prometendo a acomodação individual à ordem de coisas, só pode ser falseada.

Se as humanidades renunciam a esse compromisso prático com o esclarecimento dos núcleos de uma socialidade danificada, sua identidade fica em suspeição. Afinal, um dos sinais de crise na área é também um problema de definição mínima, pois o termo "humanidades" pressupõe a existência de um significado claro que institua alguma unidade curricular entre as disciplinas especializadas (PERLOFF, 2004). A unidade curricular pode ser costurada justamente a partir da capacidade de reflexão crítica sobre a sociedade contemporânea. Se a ausência dessas referências torna opaca a utilidade e a aplicação dos saberes, produzindo resultados pouco tangíveis e impactando a empregabilidade (JAY, 2014), a função da área fica suscetível a uma crise permanente.

As humanidades reivindicaram legitimidade epistemológica própria sob um regime de saber que valorizava o fundo histórico da cultura, ou seja, uma perspectiva desenvolvimentista que estabilizava um sentido para a origem das criações socioculturais. Nesse registro, a compreensão das nações e do presente implicava a decomposição dos objetos a partir de um cronótopo que ressaltava a formação (NARITA, 2021a). Como ciências históricas, o lugar das humanidades era garantido pela gênese: pela busca da unidade de uma causa que estabelecia temporalmente a identidade entre o objeto e sua origem (FOUCAULT, 2015, p. 55). Quando Wilhelm Dilthey (1922, p. 25), na ponta final do idealismo alemão, afirmava que as ciências humanas tornavam inteligíveis os sedimentos (Niederschläge) tradicionais do trabalho cultural, ele circunscrevia o material, justificando sua legitimidade epistemológica, à síntese hermenêutica do espírito capaz de ordenar geneticamente a tarefa interpretativa da consciência histórica. Reconhecendo a progressiva especialização da área, a indagação epistemológica tendia a legitimar as disciplinas das humanidades ao harmonizá-las conceitualmente sob o primado da compreensão e da interpretação (DILTHEY, 1922, p. 115-117). O esquema de fundamentação, portanto, abre mão de justificativa prática. Por outro lado, os espaços de educação contemporâneos, os significados públicos da história, as mídias e os sistemas de ensino (pressionados pela instrumentalização do ensino e do mercado de trabalho), signos do capitalismo avançado, compelem justamente a uma consciência prática da área.

Tornar os componentes reflexivos (conceituais) práticos é o desafio para qualquer atividade intelectual preocupada com a intervenção esclarecida na vida pública. Via ensino e tematização crítica da formação social, a história pode orientar interfaces com outros domínios das ciências humanas justamente pelo fundo histórico próprio a qualquer fenômeno 
Fronteiras - Revista Catarinense de História | https://periodicos.uffs.edu.br/index.php/FRCH/index

ISSN 2238-9717 | n. 37, p. 247-270, jul.-dez./2021 | DOI: https://doi.org/10.36661/2238-9717.2021n37.12325

sociocultural. Se o trabalho interdisciplinar é indispensável, a questão é refletir a respeito das condições sob as quais essa operação pode ser feita. Especialmente na didática histórica, linhas metodológicas e propostas teóricas há muito questionam a primazia de um ensino confinado a fatos, mas um passo epistemológico pode ser adicionado: a busca pela particularidade (situações circunscritas a contextos) não pode afastar o ensino de história do engajamento crítico - ou seja, capaz de desnaturalizar a validade de pressupostos (NARITA, 2021a) - com a nossa atualidade. Leituras pedestres do receio de "anacronismo" (utilizadas como subterfúgio para qualquer fuite en avant do engajamento crítico com o presente) e a superespecialização do conhecimento histórico, ecoando problemas de formação de professores e pesquisadores dentro das universidades, tendem a condenar o ensino e a função do conhecimento a um papel secundário na reprodução cultural. Aliás, se as humanidades sucumbem à superespecialização, elas são tragadas pela mesma lógica que torna os currículos escolares reféns de apostas aplicáveis e da pura rentabilidade - discursos que desmontam as próprias humanidades e esvaziam a reflexividade da cidadania ao estreitar o ensino em um jogo de competências técnicas circunscritas a domínios monográficos e disciplinares estreitos.

A disrupção tecnológica e a adaptação curricular à reprodução prática do mercado de trabalho, somadas às incertezas decorrentes de sucessivas crises socioeconômicas, amplificam a percepção de desorientação quanto ao ensino de história. Os espaços de educação e as humanidades digitais são frentes importantes para que o conhecimento incorpore as relações sociotécnicas e dialogue com os públicos. Mas esses pontos não substituem o compromisso intelectual da história e dos sistemas escolares, esteios da formação, com a dimensão do humano e com a reflexão sobre suas circunstâncias de ação no mundo comum: a consciência de uma condição temporal da existência (a historicidade) capaz de explicar criticamente horizontes coletivos.

\section{Referências bibliográficas}

ABUD, Katia; SILVA, André Melo; ALVES, Ronaldo. Ensino de história. São Paulo: Cengage Learning, 2010.

AGAMBEN, Giorgio. Requiem per gli studenti. Instituto Italiano per gli Studi Filosofici, Roma, 22 maio 2020.

ANDINA, Tiziana. Truth, lies, and post-truth. In: CONDELLO, Angela. Post-truth, philosophy and law. Londres: Routledge, 2019.

ANHORN, Carmen Gabriel. Teoria da história, didática da história e narrativa: diálogos com Paul Ricoeur. Revista Brasileira de História, São Paulo, v. 32, 2012.

ARANTES, Paulo Eduardo. Formação e desconstrução: uma visita ao museu da ideologia francesa. São Paulo: Editora 34, 2021.

BALDACCI, Cristina. Archivi impossibili. Turim: Johan \& Levi, 2016. 
Fronteiras - Revista Catarinense de História | https://periodicos.uffs.edu.br/index.php/FRCH/index

ISSN 2238-9717 | n. 37, p. 247-270, jul.-dez./2021 | DOI: https://doi.org/10.36661/2238-9717.2021n37.12325

BENKLER, Yochai. The wealth of networks: how social production transforms markets and freedom. New Haven: Yale University Press, 2006.

BETTIG, Roland. Copyrighting culture: the political economy of intellectual property. Boulder: Westview Press, 1996.

BEYLIS, Guillermo; JAEF, Roberto; MORRIS, Michael; SEBASTIAN, Ashwini; SINHA, Rishabh. Efecto viral: covid-19 y la transformación acelerada del empleo en América Latina y el Caribe. Washington: Banco Mundial, 2020.

BITTENCOURT, Circe. Reflexões sobre o ensino de História. Estudos Avançados, São Paulo, v. 32, 2018.

BUFACCHI, Vittorio. Truth, lies and tweets: a consensus theory of post-truth. Philosophy \& Social Criticism, Londres, v. 47, n. 3, 2020.

CAMERON, Duncan. The museum, a temple or the forum. Curator, v. 14, 1971.

CANAVESE, Mariana. Los usos de Foucault en Argentina. Buenos Aires: Siglo XXI, 2015.

CARDOSO, Oldimar. Para uma definição de didática da história. Revista Brasileira de História, São Paulo, v. 28, n. 55, 2008.

CASTRO-GÓMEZ; Santiago; GROSFOGUEL, Ramón. El giro decolonial: reflexiones para una diversidad epistémica más allá del capitalismo global. Bogotá: Siglo del Hombre Editores, 2007.

CARRETERO, Mario; MONTANERO, Manuel. Enseñanza y aprendizaje de la historia: aspectos cognitivos y culturales. Cultura y Educación, v. 20, 2008.

CAUVIN, Thomas. Public history. Londres: Routledge, 2016.

CEPAL. Estado de la banda ancha en América Latina y el Caribe. Santiago: ONU, 2018.

CRYMBLE, Adam. Technology and the historian: transformations in the digital age. Champaign: University of Illinois Press, 2021.

CURY, Marilia Xavier. Lições indígenas para a descolonização dos museus. Cadernos CIMEAC, Uberaba, v. 7, n. 1, 2017.

DILTHEY, Wilhelm. Einleitung in die Geisteswissenschaften: Versuch einer Grundlegung für das Studium der Gesellscahft und der Geschichte. Leipzig: Teubner, 1922. (Gesammelte Schriften I)

FAGUNDES, Gustavo Godoy. Livro didático, ensino de história e formação identitária nos anos iniciais do ensino fundamental. 102 f. Dissertação (Mestrado em Planejamento e Análise de Políticas Públicas) - Universidade Estadual Paulista "Júlio de Mesquita Filho", Franca, 2020.

FANON, Frantz. Peau noire, masques blancs. Paris: Seuil, 1952.

FARIA, Rafael Emilio. Reprodução de paradigmas: o conceito de colonialidade para análise dos livros didáticos de história. Dissertação (Mestrado em Planejamento e Análise de Políticas Públicas) - Universidade Estadual Paulista "Júlio de Mesquita Filho", Franca, 2021. (em preparação).

FLORESCANO, Enrique. El patrimonio nacional de México. Mexico, DF: Fondo de Cultura, 1997. (2 vols.)

FLORESCANO, Enrique. La historia debe formar al ciudadano y desarrollar sus habilidades para su aportación social. Actas, v. 3, 2006.

FONSECA, Sérgio César; NARITA, Felipe Ziotti. Conflito e cultura histórica. In: MARTINO, Vânia. Ensino de história I. Curitiba: CRV, 2018.

FONTAL MERILLAS, Olaia. Educación patrimonial: retospectiva y prospectivas para la próxima década. Estudios Pedagógicos, v. 42, 2016.

FONTANA, Josep. Qué historia enseñar?. Clio \& Asociados, v. 7, 2004.

FOUCAULT, Michel. Qu'est-ce que la critique? Critique et Aufklärung (1978). Paris: Vrin, 2015. 
Fronteiras - Revista Catarinense de História | https://periodicos.uffs.edu.br/index.php/FRCH/index

ISSN 2238-9717 | n. 37, p. 247-270, jul.-dez./2021 | DOI: https://doi.org/10.36661/2238-9717.2021n37.12325

GARCÍA VALECILLO, Zaida. Estrategias educativas para la valoración del patrimonio cultural en la educación básica en Venezuela. Educere, Bogotá, v. 11, 2007.

GIDDENS, Anthony. A vida em uma sociedade pós-tradicional. In: GIDDENS, Anthony; LASH, Scott; BECK, Ulrich. Modernização reflexiva. São Paulo: Editora Unesp, 2012.

GARCIA CANCLINI, Nestor. Ciudadanos reemplazados por algoritmos. Guadalajara: Universidad de Guadalajara, 2020.

GIORDANO, Verónica; RODRÍGUEZ, Gina Paola. Memorial struggles and power strategies of the rights in Latin America today. Universitas, Quito, v. 31, 2019.

GÓMEZ CARRASCO, Cosme; RODRÍGUEZ PÉREZ, Raimundo. La historia como materia formativa: reflexiones epistemologicas e historiográficas. Revista de Historiografía, v. 27, 2017.

GRANJA MATIAS, Simon. No volverá la cátedra de historia a los colegios. El Tiempo, Bogotá, 17 jan. 2018.

GRECO, Gian; FLORIDI, Luciano. The tragedy of the digital commons. Ethics and Information Technology, v. 6, n. 2, 2004.

HABERMAS, Jürgen. Strukturwandel der Öffentlichkeit. Frankfurt am Main: Suhrkamp, 1990. HALL, Stuart. The question of cultural identity. In: HALL, Stuart; HALL, David; MCGREW, Tony. Modernity and its futures. Londres: Polity, 1992.

HEIDEGGER, Martin. Ontologie: Hermeneutik der Faktizität. Frankfurt am Main: Vittorio Klostermann, 1988. (Gesamtausgabe 63)

JAY, Paul. The humanities crisis and the future of literary studies. Nova York: Palgrave Macmillan, 2014.

KUDLÁCOVÁ, Blanka. History of education and historical-educational research in Slovakia through the lens of European context. Espacio, Tiempo y Educación, v. 3, 2016.

LE GOFF, Jacques. L'histoire nouvelle. In: LE GOFF, Jacques. La nouvelle histoire. Paris: Éditions Complexe, 2006.

LEGÊNE, Susan; AKKER, Chiel. Museums in a digital culture. Amsterdam: Amsterdam University Press, 2020.

LESSIG, Lawrence. Code and other laws of cyberspace. Nova York: Basic Books, 1999.

LOUKISSAS, Yanni. All data are local. Cambridge: MIT Press, 2019.

MALDONADO-TORRES, Nelson. Outline of ten theses on coloniality and decoloniality. Foundation Frantz Fanon, Paris, 26 out. 2016.

MANOEL, Ivan Aparecido. O ensino de história no Brasil: origens e significados. Cadernos CIMEAC, Uberaba, v. 1, n. 1, 2011.

MANOVICH, Lev. Cultural data: possibilities and limitations of the figital data universe. In: GRAU, Oliver; COONES, Wendy; RÜHSE, Viola (ed.). Museum and archive on the move: changing cultural institutions in the digital era. Berlin: Gruyter, 2017.

MAXWELL, W. David. The plight of the humanities. Journal of Aesthetic Education, v. 3, n. 2, 1969.

MCCULLOCH, George. History of education. In McCulloch, G.; Crook, D. (eds.). The Routledge International Encyclopedia of Education. Londres: Routledge, 2008.

MEMMI, Albert. Le racisme. Paris: Gallimard, 1982.

MENESES, Ulpiano. A problemática da identidade cultural nos museus. Anais do Museu Paulista, São Paulo, n. 1, 1993.

MESA MADRID, Miguel; ZÁPATA GIRALDO, Edwin. Entretejiendo prácticas decoloniales en la enseñanza de la historia. $140 \mathrm{f}$. Monografia (Licenciatura em Ciências Sociais) Universidade de Antioquia, Medellín, 2017.

MESA Y LEOMPART, José. Compendio de la historia de América. Paris: Rosa y Bouret, 1870. (2 vols.) 
Fronteiras - Revista Catarinense de História | https://periodicos.uffs.edu.br/index.php/FRCH/index ISSN 2238-9717 | n. 37, p. 247-270, jul.-dez./2021 | DOI: https://doi.org/10.36661/2238-9717.2021n37.12325

MIGNOLO, Walter. Educación y decolonialidad: aprender a desaprender para poder reaprender. Revista del IICE, v. 35, 2014.

MIGNOLO, Walter. Local histories, global designs: coloniality, subaltern knowledges, and border thinking. Princeton: Princeton University Press, 2010.

MORELOCK, Jeremiah; NARITA, Felipe Ziotti. The society of the selfie: social media and the crisis of liberal democracy. Londres: University of Westminster Press, 2021.

NARITA, Felipe Ziotti. Ainda aprender com a história?. In: FONSECA, Sérgio César; JESUS, Carlos Gustavo. Ensinar história: currículos, práticas e sujeitos. São Paulo: Millennium Books, 2021a.

NARITA, Felipe Ziotti. A educação da sociedade imperial. Curitiba: Appris, 2017.

NARITA, Felipe Ziotti. Between a double crisis. In: PIEKARSKA, Anna; JUSKOWIAK, Piotr; KRZESKI, Jakub; SZADKOWSKI, Krystian. Commoning: the common as a process of critique, struggle and change. Poznan: Praktyka Teoretyczna, 2020.

NARITA, Felipe Ziotti. Educação, vida urbana e moralidade: a elaboração do povo e a invenção do social no fim de século brasileiro. 378 f. Relatório (Pós-doutorado) - Universidade de São Paulo, Ribeirão Preto, 2019.

NARITA, Felipe Ziotti. Morale scolaire et transculturation dans l'espace atlantique au XIXe siècle. In: FONTAINE, Alexandre. Penser la circulation de savoirs sacolaires dans le monde transatlantique. Lormont: Le Bord de l'eau, 2021b.

NARITA, Felipe Ziotti. O século e o império: tempo, história e religião no segundo reinado. Curitiba: Appris, 2014.

NARITA, Felipe Ziotti. Para uma nova figuração da práxis: a teoria social e o princípio do comum. Pós Ciências Sociais, São Luís, v. 15, 2018a.

NARITA, Felipe Ziotti. Unlimited capitalism and the politics of the common. In: RATAJCZAK, Mikolaj; BLESZNOWSKI, Bartlomiej. Cooperation as the institution of the common. Poznan: Praktyka Teoretyczna, 2018b.

NARITA, Felipe Ziotti; KATO, Danilo Seithi. Construção democrática e educação popular: para um esquema interpretativo da América Latina. Cadernos CIMEAC, v. 10, n. 3, 2020.

NUSSBAUM, Marta. Not for profit: why democracy needs the humanities. Princeton: Princeton University Press, 2010.

PANDEL, Hans-Jürgen. Geschichtsdidaktik. Berlim: Wochenschau, 2017.

PANDEL, Hans-Jürgen. Geschichtskultur. In: MAYER, Ulrich (Org.) Wörterbuch Geschichtsdidaktik. Schwalbach: Wochenschau, 2006.

PÉREZ HERRERO, Pedro; GARCIA FERNÁNDEZ, Gonzalo. La importancia de la enseñanza de la historia para el futuro de los estudiantes. The Conversation, Nova York, 7 ago. 2019.

PERLOFF, Marjorie. Crisis in the humanities?. In: PERLOFF, Marjorie. Differentials: poetry, poetics, pedagogy. University of Alabama Press, 2004.

PETRAZZINI, Ben. Digital poverty: Latin American and Caribbean perspectives. Warwickshire: Intermediate Technology Publications, 2007.

PLÁ, Sebastián. La enseñanza de la historia como objeto de investigación. Secuencia, México DF, v. 84, 2012.

PLUMB, John. Crisis in the humanities. Baltimore: Penguin, 1964.

POMIAN, Krzysztof. Des saintes reliques à l'art moderne. Paris: Galliard, 2003.

PRIETO, Guillermo. Compendio de historia universal. Mexico: El Gran Libro, 1888.

RAMALLO, Francisco. Narrativas descoloniales, (re)escrituras de la historia y enseñanzas otras. Educación, Lenguaje y Sociedad, v. 14, 2017.

RESTREPO, Eduardo; ROJAS, Axel. Inflexión decolonial: fuentes, conceptos y cuestionamientos. Bogotá: Editorial Universidad del Cauca, 2010.

RHEINGOLD, Howard. The virtual community. Cambridge: MIT Press, 2000. 
ROCA, Andrea. Acerca dos procesos de indigenização dos museus. Mana, Rio de Janeiro, v. 21, 2015.

ROSNAY, Mélanie; STALDER, Felix. Digital commons. Internet Policy Review, v. 9, n. 4, 2020.

RÜSEN, Jörn. Lebendige Geschichte. Göttingen: Vandenhoeck \& Ruprecht, 1989.

SCHEINER, Livia. Formação histórica em alunos do ensino de jovens e adultos. In: NARITA, Felipe Ziotti; CUNHA, Marcus Vinicius; SILVA, Tatiane (Orgs.). Educação em perspectiva histórica. Franca: História e Cultura, Unesp, 2015.

SCHMIDT, Maria Auxiliadora; BARCA, Isabel; URBAN, Ana Claudia. Passados possíveis: a educação histórica em debate. Ijuí: Unijuí, 2014.

SCHNAPP, Jeffrey; PRESNER, Todd. Manifeste pour des humanités numériques 2.0. Multitudes, Paris, v. 59, 2015.

SHORTER, Edward. The historian and the computer. Nova York: Prentice Hall, 1971.

SIERRA, Justo. Compendio de historia de la antigüedad. México DF: UNAM, 1984 [1880]. (Obras completas, vol. 10)

SÖDERBERG, Johan. Copyleft vs. copyright. First Monday, Chicago, v. 7, n. 3, 2002.

SORJ, Bernardo; MARTUCCELLI, Danilo. O desafio latino-americano: coesão social e democracia. Rio de Janeiro: Civilização Brasileira, 2008.

SPIVAK, Gayatri. Can the subaltern speak?. In: WILLIAMS, Patrick. Colonial discourse and post-colonial theory. Heartfordshire: Harvester Wheatsheaf, 1994.

TERRANOVA, Tiziana. Network culture: politics for the information age. Londres: Polity Press, 2004.

TRIGO, Benigno. Foucault and Latin America. Londres: Routledge, 2002.

VARINE, Hugues. L'initiative communautaire. Paris: Éditions Mnes, 1991.

WRIGHT MILLS, Charles. The power elite. Oxford: Oxford University Press, 1999.

\section{Agradecimento}

Registro meus agradecimentos aos pareceristas anônimos, pois o engajamento crítico com o artigo foi fundamental para que eu pudesse aperfeiçoá-lo. Também agradeço ao colega e exorientador Sérgio César da Fonseca (USP) e ao pesquisador Carlos Gustavo Jesus (PUC-SP) pela interlocução. 